\title{
Pharmacological Effects of RAAS Blockade in Ischemic Nephropathy
}

\author{
Laura Rivoli $^{1}$, Francesca Di Mario ${ }^{2}$, Giuseppe Coppolino ${ }^{3}$, Antonietta Gigante, ${ }^{2, *}$, Biagio Barbano ${ }^{2}$, \\ Tariq E. Farrah ${ }^{4}$, Edoardo Rosato ${ }^{2}$, Giorgio Fuiano ${ }^{1}$ and Rosario Cianci $^{2}$
}

\begin{abstract}
${ }^{I}$ Nephrology and Dialysis Unit, Magna Graecia University, Catanzaro, Italy; ${ }^{2}$ Department of Clinical Medicine, Sapienza University of Rome, Italy; ${ }^{3}$ Nephrology and Dialysis Unit, "Pugliese-Ciaccio" Hospital, Catanzaro, Italy; ${ }^{4}$ Department of Renal Medicine, Royal Infirmary of Edinburgh, United Kingdom
\end{abstract}

\begin{abstract}
The management of ischemic nephropathy due to atherosclerotic renal artery stenosis has become increasingly conservative in the modern era, with current guidelines recommending optimized medical therapy as the initial step. The doubts raised by the recently published trials of revascularization strategies have led to a renewed focus on pharmacological strategies promoting blood pressure control and renal protection. It is essential to further elucidate the pathophysiological mechanisms underlying hypoperfusion induced renal microvascular dysfunction with subsequent tissue injury and fibrogenesis. The role of renin angiotensin aldosterone system as a mediator of the main pathophysiological consequences of ischemic nephropathy is well known. However, more recent experimental evidence on the adrenergic system and intrarenal tubular feedback mechanisms has stimulated new interest towards a multi-target therapeutic approach. This review focuses on the pharmacology of the principle therapeutic drug classes currently used in the treatment of atherosclerotic renal artery stenosis with an analysis of their metabolic aspects and use in clinical practice based on evidence from clinical trials.
\end{abstract}

Keywords: Chronic kidney disease, renal artery stenosis, ischemic nephropathy, ACE-inhibitors, angiotensin II receptors-blockers, direct renin inhibitors.

\section{INTRODUCTION}

Chronic kidney disease (CKD) is a major, worldwide health problem. The most rapidly growing age group of the population reaching end stage renal disease (ESRD) are those over 65 years of age [1]. Ischemic nephropathy (IN) associated with atherosclerotic renal artery stenosis (ARAS) is thought to account for $5-10 \%$ of incident ESRD cases [2, 3]. However, it may be an under diagnosed clinical entity and the prevalence is probably higher [3]. The term ischemic nephropathy has been used to refer to kidney injury in a variety of acute and chronic settings. For the purposes of this review, this term will encompass the reduction in glomerular filtration rate (GFR) associated with marked decrease in renal perfusion pressure in ARAS; the presence of IN implies hemodynamically significant ARAS activating neurohormonal systems involved in downstream effects leading to kidney injury and atrophy [4]. ARAS is generally associated with systemic atherosclerosis and consequently, with significant cardiovascular morbidity and mortality [511]. Early reports of renal artery revascularization for the treatment of ARAS demonstrated benefit on control of blood pressure and kidney function [1, 12-15]. However, more recent clinical trials have focused on additional well-defined clinical endpoints including cardiovascular events and accepted contemporary renal endpoints such as need for renal replacement therapy [16-18]. The CORAL study compared endovascular stenting and optimal medical therapy showing no benefit of stenting when added to medical therapy in improving cardiovascular and renal outcomes. The aim of medical therapy goal was to optimize all modifiable cardiovascular and renal risk factors including hypertension, hyperlipidemia, glycemic control, antiplatelet therapy and smoking cessation. A unique aspect of this trial was that antihypertensive therapy centered on RAAS blockade [16]. RAAS plays an essential role in both kidney metabolic demand and cardiovascular morbidity [19]. Drugs that block the RAAS have been shown to be helpful in preventing downstream effects of ARAS in the kidney and cardiovascular

*Address correspondence to this author at the Department of Clinical Medicine, "Sapienza" University of Rome, Viale del Policlinico 155, Rome, Italy; Tel:/Fax: +390649972074; E-mail: antonietta_gigante@yahoo.it systems [20]. In this review, we will explore the pharmacologic aspects of drugs that act on the RAAS and their use in the clinical management of patients with ARAS and associated CKD.

\section{RAAS ROLE IN CHRONIC ISCHEMIC NEPHROPATHY AND EXPERIMENTAL BASIS FOR RAAS BLOCKADE}

Since ARAS was identified as a possible reversible cause of hypertension and kidney impairment, the interest in the study of this condition has grown [21]. Recent evidence of RAAS inhibitors efficacy in ARAS management compared to an interventional approach warrants further scrutiny from a pathophysiological standpoint.

The comprehension of underlying mechanisms of RAAS effects has a long history begun with Goldblatt rats' models of two-kidney one-clip renal arteries. These experiments demonstrated the causal relationship between renal artery stenosis and the development of hypertension as a three stage process [22]. RAAS is clear link between renal artery obstruction and renovascular hypertension. Its activation is "traditionally" triggered by a decreased afferent arteriola shear stress, which induces Renin release with subsequent Angiotensin II (AngII) and Aldosterone production [21]. The results are a progressive vasoconstriction of efferent arteriole with an increase of intraglomerular pressure, salt and water retention with consequent volume expansion and an eventual increase of systemic blood pressure. At this stage, clip removal or ACE inhibitors (ACEIs) administration reverse high blood pressure. The second phase, after five to eight weeks from clipping, is characterized by further salt-retention and volume expansion, while RAAS begins to be down regulated. Clip removal or ACE-Is are still able to restore normal blood pressure with studies showing that, AngII is the main vasoactive mediator during this phase. Finally, in the third phase, after nine weeks from clipping, Renin and AngII activity drops down. Clip removal is no longer effective and only ACE-Is at higher doses can decrease blood pressure [22].

On the other hand, while the cause-effect link between renal artery narrowing and hypertension was well illustrated in this model, the relation between renal artery occlusion and irreversible kidney dysfunction is different and not so well defined. In fact not 
all ARAS, even when severe, results in a progressive decline in GFR. This suggests that the link between ARAS and CKD is more complex than a simple mechanical obstruction, as suggested by the differing responses seen following relief of vascular obstruction in fibromuscular dysplasia and ARAS. In fibromuscular dysplasia, restoration of flow regularly produces an improvement in both renovascular hypertension and rate of GFR decline, whereas no RCTs have clearly demonstrated the same benefit in ARAS [23, 24]. In this setting, the greater the degree chronicity and severity of the vascular occlusion, the less the likely it is that the kidney function will improved after revascularization [25]. In fact, the persistence of a chronic tissue hypoxia activates pro-inflammatory and pro-fibrotic pathways with consequent microvessels rarefaction and interstitial fibrosis [26, 27].

The term "ischemic nephropathy" should suggest that kidney failure is mainly due to hypoxic hypoperfusion, but the real contribution of low oxygen delivery to renal injury in ARAS is controversial [28]. Renal metabolic demand is much lower than renal blood flow (around 10\%) and not all parenchyma areas are equally vulnerable to decreased perfusion pressure [26]. Interestingly, studies by blood oxygen level dependent magnetic resonance (BOLDMR) have demonstrated that mild or moderate reduction in renal perfusion pressure (up to $40 \%$ ) and in renal blood flow (up to $30 \%$ ) does not induce severe renal cortex hypoxia. Only a "critical" stenosis (70 to $80 \%$ ) induces cortical hypoxia and relevant pressure gradient [29]. Therefore, hypoxia is not the sole determinant, as other factors such as hypertension, atherosclerosis and endothelial dysfunction are also involved in inducing parenchymal vascular injury and chronic renal impairment [30]. Indeed, the above threestage process has been studied extensively when renal artery lesions are severe, whilst the role of less severe flow reductions in inducing renal dysfunction is not well-defined [31]. Textor proposed that the contemporary interaction between renal hypoperfusion and persistent RAAS activation accelerates atherosclerosis progression [32]. Alternatively, atherosclerosis could aggravate the process, leading to persistent GFR reduction by triggering and amplifying the activation of several pro-inflammatory and pro-fibrotic pathways [33, 34]. In ARAS, the renal vascular endothelium is exposed to multiple injuries, as a consequence of the simultaneous presence of atherosclerotic inflammation, hypertension, RAAS-induced vasoconstriction and reduced bioavailability of the vasodilator nitric oxide [35].

In turn, endothelial dysfunction reduces vascular proliferative capacity, migratory properties and blunts protection from inflammatory cell infiltration [36, 37]. The consequence is a progressive injury that starts with tubulointerstitial changes and continues with glomerulosclerosis, tubulointerstitial fibrosis and/or vascular sclerosis, leading to irreversible scarring [38]. Recent evidence suggests that RAAS activation is the central feature of all these interactions, by mediating all hemodynamic intra- and extra-renal consequences of ARAS [39, 40].

It has also been clearly demonstrated that RAAS inhibitors have reno-protective and antiproteinuric effects, due to their action in regulating intra-glomerular pressure, reducing arterial pressure and dilating efferent arterioles [41]. Moreover, studies in both animal and human models have confirmed cross-talk between RAAS activation and atherosclerosis [41]. In fact, AngII is able to stimulate intracellular signaling pathways, which promote enzymatic production of oxygen-derived free radicals (ROS), oxidation of LDL, endothelial impairment, matrix degradation and thrombosis [42-44]. Thus, AngII promotes post-ischemic injuries in hypertensive kidney by inducing oxidative stress $[45,46]$.

As a consequence, the antioxidant effects of RAAS blockade could be important in preventing chronic IN. However, while acute AngII effects in renovascular hypertension are well known [47, 48], the long-term consequences of increased levels of AngII (and related oxidative stress) for renal function in the 2-Kidneys 1-Clip model have not been extensively studied. Nevertheless, there is experimental evidence that the renal damage due to prolonged arterial narrowing is mainly due the oxidative stress elicited by the increased production of AngII [49]. Therefore, the observed beneficial effects of RAAS blockade are due in part to improvement in renal hemodynamic, and in part to beneficial effects on oxidative stress endothelial function, systemic inflammation, and fibrosis, as reported by studies comparing RAAS inhibitors with other antihypertensive drugs $[50,51]$.

\section{PHARMACOLOGICAL ASPECTS OF RAAS BLOCKADE}

RAAS is a hormonal system exerting an essential role in regulation of blood pressure, extracellular volume and tissue perfusion. Renin secretion is stimulated by decreased perfusion pressure, increased $\mathrm{NaCl}$ delivery and adrenergic hyperactivity [52]. Renin starts the first step of the RAAS by cleaving the $\mathrm{N}$-terminal portion of Angiotensinogen, to produce the biologically inert decapeptide AngI. Angiotensinogen is produced by liver, although its mRNA can be detected in many other tissues including kidney, brain, heart, vascular, adrenal gland, ovary, placenta, and adipose tissue and its circulating levels are constitutively stable [53]. The second step is AngII synthesis through the hydrolyzation of AngI by Angiotensinconverting enzyme (ACE), a membrane-bound exopeptidase localized on the plasma membranes of various cell types. AngII is the primary active product of RAAS and the most important product, stimulating AngII specific receptors and Aldosterone release [54, 55].

However, recent evidences have added new insights into the RAAS. Firstly, it has been discovered that AngII has at least 4 Angiotensin receptor subtypes. The type 1 (AT1) receptor predominantly mediates established and "canonical" physiological effects, such as vasoconstriction, increased blood pressure, increased cardiac contractility, vascular and cardiac hypertrophy, stimulation of Aldosterone synthesis, renal tubular sodium reabsorption and inhibition of renin release. The AT1 receptor also mediates effects of AngII on cell growth and proliferation, inflammatory responses, oxidative stress and establishing the ACE/AngII/AT1 receptors axis [56]. The type 2 (AT2) receptors have different effects. Indeed, AT2 receptors stimulation exert antiproliferative, pro-apoptotic and vasodilator action possibly due to bradykinin release [55]. Recently AT4 receptors were identified by molecular cloning [57]; they have a very low affinity for AngII and AT1 and AT2 receptor antagonists, but they might mediate many physiological functions related to cognition, cardiovascular and renal metabolism, and are implicated in diabetes and hypertension [57].

AT receptor distribution and mutual balance in tissues and organs are also crucial. In kidneys, their subtypes are not equally represented [58]. AT1 receptors are the principal receptors in renal vessels and mesangium and, in fact, they are particularly involved in renal vessels vasoconstriction as well as mesangial cells contraction. On the other hand, AT2 receptor stimulation produces sodium excretion, increases renal blood flow and attenuates tissue inflammation [59].

Recent evidence has shown the existence of a "tissue" renin Angiotensin system in which local AngII biosynthesis may be activated by Renin and/or Angiotensinogen taken up from bloodstream [60]. This tissue system is responsible for the vascular and cardiac remodeling action of RAAS and of main the intrarenal dynamics.

Moreover, other AngI and II metabolites (AngIII and IV) could have tissue activity and new findings about ACE2 pathways and its products, Ang-1-7 and Ang-1-9 have been reported. These two vasoactive peptides act through the Mas receptor (MasR) and AT2R, respectively. The ACE2/Ang-1-7/MasR and ACE2/Ang-19/AT2R axes have opposite effects to those of the ACE/Ang II/AT1R axis, such as decreased proliferation, reduced cardiovascular remodeling, increased production of nitric oxide and vasodilatation [61]. These discoveries could give a boost to the newest pharmacological perspectives also in ARAS and IN [62]. 
Before the introduction of ACE-Is in renovascular disease management, less than half of patients achieved a satisfactory blood pressure control, despite multidrug therapy, leading even to the necessity of performing rescue bilateral nephrectomy in the drug unresponsive patients [63]. Available medications were mostly sympatholytic or vasodilator agents, beta-blockers and diuretics, which could not counteract the pathophysiological mechanisms underlying the elevated blood pressure [20]. Today, between 80 and $100 \%$ of renovascular hypertension patients achieve a target blood pressure using drugs acting on RAAS. The first discovered and tested ACE-I in renovascular hypertension was Saralasin. Since then, several studies on both animal models and humans have shown the positive effect of RAAS blockade to limit hemodynamic mechanisms central to the hypertension of ARAS and its consequences [64]. Furthermore, the non-hemodynamic effects of ACEIs on endothelial function, vascular remodeling and neuro-hormonal activation have been discovered in a variety of clinical setting, clarifying the mechanisms underlying their cardio-protective and renoprotective power $[10,65]$. In $\mathrm{CKD}$ populations, many controlled clinical trials and RCTs have highlighted the positive effect of ACE-I/ARB treatment, not only due to their antihypertensive effects but also to their anti-proteinuric activity that provides a significant renoprotection [41]. Nevertheless the use of this class of drugs in ARAS has always raised concerns, mainly because the blockade of RAAS in patients with hemodynamically significant stenosis, in some cases, leads to an acute deterioration in renal function. This is usually caused by the reduction in glomerular blood flow reserve that, in absence of anti-Angiotensin drugs, is maintained almost exclusively by AngII-induced efferent vasoconstriction [66].

Despite this, large RCTs reported that only fifty percent of patients with IN experience a mild and reversible decline in GFR after few days of therapy with ACE-Is, while greater and persistent decline GFR decline occurred in five to ten percent of treated subjects. Indeed, ACE-I induced decline in GFR is almost absent in the case of unilateral stenosis with normal contra-lateral kidney blood flow [67]. ACE-I-induced renal dysfunction has also been described in some patients with nephrosclerosis and normal main renal arteries [13]. Therefore it is not justified to avoid the use of RAAS inhibitors in ARAS in the absence of significant negative effects on renal function.

\section{ACE-I PHARMACOLOGY}

ACE-Is can be classified into three categories based on chemical structure: those containing a sulfhydryl group similar to Captopril (Fentropril, Peralotril, Zofenopril, Alacepril); those containing a carboxyl group similar to Enalapril (Lisinopril, Benazepril, Quinapril, Maexipril, Ramipril, Spirapril, Perindopril, Indolapril, Pentopril, Enalapril, Cilazapril) and those containing a phosphorus group related to Fosinopril [68]. Although acting in the same way, not all ACE-Is are equally helpful in all clinical settings [69]. The difference among various molecules depends on their chemical structure and therefore on their potency, bioavailability, plasma half-life, distribution and affinity for tissue-bound ACE. Mechanisms become even more complex in a context like IN in which the renal hemodynamic and metabolic responses are modified. Factors complicating ACE-Is pharmacology are: 1) the presence of two binding sites for ACE-I drugs with different binding constants and catalytic substrate selectivity [70]; 2) the extremely high ACE enzyme affinity for its inhibitors [71]; 3) almost all ACE-Is are administered orally, but the characteristics of all active and inactive metabolites are little known; 4) almost 90\% of ACE-Is pharmacological effects depends on the binding with tissutal enzymes. In general ACE-Is work by blocking the activity of ACE and kininase II, preventing the conversion of AngI to AngII thus reducing circulating and local levels of AngII. ACE-Is also decrease Aldosterone and vasopressin secretion and sympathetic nerve activity, but there is controversy regarding their efficacy in blocking other "tissue" actions of the RAAS [72-74]. Moreover ACE is a dipeptidyl carboxyl metallopeptidase found in tissues and in circulation and located at the center of two main antagonistic blood pressure regulatory systems: the RAAS and the bradykinin system.

Bradykinin system regulates smooth muscle contraction and increases vascular permeability and vasodilation. Bradykinin also causes natriuresis through direct tubular effects [75].

As already mentioned, ACE-Is are a heterogeneous class drug as summarized in Table 1 [76]. Regarding to half-life, the shortest one is Captopril, while most parts have a long half life of around 10-12 hours. Except for Fosinopril, elimination is predominantly renal, thus a dose adjustment is required in patients with impaired renal function. The majority of ACE-Is are prodrugs that remain inactive until esterified in the liver. These prodrugs have enhanced oral bioavailability compared with their active drugs [68]. For example, Ramipril, the most widely used, administered at a single dose ranging from $2.5 \mathrm{mg}$ to $20 \mathrm{mg}$ inhibits ACE activation by 60 $80 \%$ in four hours and this effect still lasts by $40-60 \%$ after 24 hours. If we administer multiple (14 days) doses of few amounts of Ramipril (5.0 mg once daily), ACE activation will be inhibited until $90 \%$ after four hours and $80 \%$ after 24 hours. This effect is related to saturation of ACE enzyme binding sites and contemporaneous slowed enzymatic release [77]. However the pharmacodynamics of ACE-Is cannot be evaluated just by considering its ability to inhibit the activity of sieric ACE enzyme. Importantly, the in vitro ability of various ACE-Is to bind ACE in different homogenized tissues varies depending on the molecule. Therefore, we should take into account the ability of the different molecules to bind tissutal ACE. Fabris et al., analyzed the binding of various ACE-Is to heart homogenates and found the following order of potency: quinaprilat = benazaprilat $>$ perindoprilat $>$ lisinoprilat $>$ fosinoprilat. The clinical relevance of this observation is still undefined [78]. Considering previous pathophysiological findings about the relative importance of cardiovascular and endothelial protection, anti-atherosclerotic and antioxidant effects than hemodynamically pressor action, we could infer that it is better to choose RAAS blockers molecules with greater proven pleiotropic effects profile rather than a pharmacological approach [79]. Perindopril and Ramipril have been shown to have a longer duration of action, higher lipophilicity, and stronger tissue ACE inhibiting properties compared with other ACE-Is, These features have made these two drugs the most chosen for CV prevention [80]. Even in terms of endothelial protection Perindopril and Ramipril have demonstrated the best protection against endothelial apoptosis. In particular, a probable order of potency of ACEIs could be Perindopril $>$ Ramipril $\gg$ Quinapril $=$ Trandolapril $=$ Enalapril, with significant differences between Perindopril and Quinapril ( $\mathrm{P}<0.01)$, Trandolapril $(\mathrm{P}<0.001)$, and Enalapril $(\mathrm{P}<$ 0.001). Perindopril demonstrated also to have superior antiinflammatory properties compared to Enalapril, although, most studies and RCTs in ARAS used Enalapril [20].

\section{ARBS PHARMACOLOGY}

ARBs were synthesized as a newer RAAS-modulating class of antihypertensive agents [81]. They reduce blood pressure by blocking AngII-induced vasoconstriction and decreasing catecholamine, Aldosterone and Vasopressin release. Simultaneously ARBs blunt salt and water intake [82]. These substances differ from ACE-Is since they selectively inhibit AngII effects antagonizing AT1 [83]. Ang II is produced not only by ACE, but also by many other enzymatic non-renin pathways, such as tonin or cathepsin, trypsin and chymase [84]. Therefore ARBs, by directly and more specifically inhibiting AT1 may have a more targeted pharmacological action. The US Food and Drug Administration approved seven of them for hypertension treatment; Losartan, Candesartan, Valsartan, Olmesartan, Irbeesartan, Telmisartan, Eprosartan [86]. Main pharmacologic features are outlined in Table $\mathbf{1}$. 
Table 1.

\section{$\underline{\text { ACE-Is }}$}

Mechanism of action: Block the activity of ACE (or kininase II), decrease Aldosterone and vasopressin secretion and sympathetic nervous activity Indications: Treatment of hypertension and heart failure, delay in progression of chronic non-diabetic and diabetic renal disease, renovascular disease management

Main common side effects: Increase risk of angioedema, hypotension, cough, AKI, hyperkaliemia

\begin{tabular}{|l|c|c|c|c|c|c|}
\hline & $\begin{array}{c}\text { Half life } \\
\text { (h) }\end{array}$ & $\begin{array}{c}\text { T max } \\
(\mathbf{h})\end{array}$ & $\begin{array}{c}\text { Renal elimination } \\
(\boldsymbol{\%})\end{array}$ & ARAS/IN trial & $\begin{array}{c}\text { Doses used in } \\
\text { major trials (mg) }\end{array}$ & $\begin{array}{c}\text { Dose range } \\
(\mathbf{m g})\end{array}$ \\
\hline \hline Captopril & 2 & $1-2$ & $80 \%$ & Hollenberg et al & $100-150$ & $25-150$ \\
\hline Enalapril & $2-6$ & 1 & $60 \%$ & $\begin{array}{c}\text { Franklin } \text { et al., } \\
\text { Hodsman } \text { et al., } \\
\text { Reams } \text { et al. }\end{array}$ & $20-40$ & $10-40$ \\
\hline Fosinopril & 12 & $1-3$ & $50 \%$ & NR & $20-40$ \\
\hline Benazepril & $10-11$ & $1-2$ & $90 \%$ & NR & 30 & $20-40$ \\
\hline Lisinopril & 12 & 6 & $100 \%$ & NR & $20-40$ \\
\hline Ramipril & $13-17$ & 1 & $60 \%$ & Tillman et al. & 10 & $2,5-20$ \\
\hline Perindopril & $1,5-3$ & $1-2$ & $75 \%$ & NR & 4 & $4-8$ \\
\hline ARs & & & & & 4 \\
\hline
\end{tabular}

\section{$\underline{\text { ARBs }}$}

Mechanism of action: Block AT1 receptors activity

Indications: Treatment of hypertension and heart failure, delay in progression of chronic non-diabetic and diabetic renal disease, renovascular disease management

Main common side effects: Increase risk of hypotension, AKI, hyperkaliemia

\begin{tabular}{|c|c|c|c|c|c|c|}
\hline & $\begin{array}{l}\text { Half life } \\
\text { (h) }\end{array}$ & $\begin{array}{c}\text { T max } \\
\text { (h) }\end{array}$ & $\begin{array}{c}\text { Renal elimination } \\
(\%)\end{array}$ & ARAS/IN trial & $\begin{array}{l}\text { Doses used in } \\
\text { major trials } \\
(\mathrm{mg} / \mathrm{dL})\end{array}$ & $\begin{array}{l}\text { Dose range } \\
(\mathrm{mg} / \mathrm{dL})\end{array}$ \\
\hline Valsartan & $6-9$ & $2-4$ & 10 & NR & 160 & $80-320$ \\
\hline Olmesartan & 13 & $1-3$ & $8-10$ & NR & & $20-40$ \\
\hline Irbesartan & $11-15$ & $1,5-2$ & 20 & NR & 300 & $150-300$ \\
\hline Telmisartan & 24 & $0,5-1$ & $\sim 0$ & NR & & $40-80$ \\
\hline Eprosartan & $5-9$ & $1-2$ & 7 & NR & & $400-800$ \\
\hline \multicolumn{7}{|c|}{$\begin{array}{l}\text { Mechanism of action: Direct Renin inhib } \\
\text { Indications: Treatment of hypertension }\end{array}$} \\
\hline & $\begin{array}{l}\text { Half life } \\
\text { (h) }\end{array}$ & $\begin{array}{c}T \text { max } \\
\text { (h) }\end{array}$ & $\begin{array}{c}\text { Renal elimination } \\
(\%)\end{array}$ & ARAS/IN trial & $\begin{array}{c}\text { Doses used in } \\
\text { major trials } \\
(\mathrm{mg} / \mathrm{dL})\end{array}$ & $\begin{array}{c}\text { Dose range } \\
(\mathrm{mg} / \mathrm{dL})\end{array}$ \\
\hline Aliskiren & 24 & $1-3$ & 25 & NR & 100 & $150-300$ \\
\hline
\end{tabular}

Similarly to ACE-Is, ARBs display different pharmacokinetic profiles, which may explain potential effectiveness difference [83]. The power of each specific molecule depends on three parameters: pressure inhibition, AT1 selectivity/affinity and half-life. Food and Drug Administration (FDA) provides in the technical sheets the differences between ARBs based on these three criteria, helping clinicians choosing the most appropriate drug in different settings of disease. Irbesartan, Candesartan, Telmisartan, and Olmesartan show a longer half-lives and duration of action than Losartan and Valsartan. 24-hour blood pressure can be better controlled by newer agents (Irbesartan, Candesartan, Telmisartan, and Olmesartan). Older ones (Losartan and Valsartan) may need twice daily admini- 
stration. Losartan's major active metabolite, EXP- 3174, is 10 to 20 times more potent than Losartan and has a longer duration of action. EXP- 3174 is the only responsible for the therapeutic effects. Candesartan and Olmesartan are pro-drugs; they are subjected to metabolic activation during absorption from the gastrointestinal tract. The parent compounds of Candesartan and Olmesartan have lower efficacy. Once Olmesartan is rapidly converted to its active metabolite, it is not subjected to further metabolism. Losartan, Candesartan, and Eprosartan have short half-lives so they require twicedaily dosing in some patients [85-87]. ARBs clearance is much less dependent on renal elimination than ACE-Is and this might represent a vantage in chronic IN patients. Beyond pharmacokinetic differences, molecular variance could lend pharmacodynamic proprieties and thus different pleiotropic actions between ARBs. At this regard difference becomes more evident if considering newer or older generation ARBs $[88,89]$. In contrast to ACE-Is, ARBs do not enhance concentrations of bradykinin, a stimulus for NO release; but they may enhance eNOS expression and this propriety could vary between different ARBs molecules [90]. Olmesartan, as compared to Losartan, Valsatan and Telmisartan, has the most beneficial effect on endothelial function and nitric oxide release. The presence of the hydroxyl group may contribute to free radical scavenging properties for Olmesartan, including chain-breaking antioxidant activity [91]. ARBs have been shown to decrease plaque grow in ApoE-deficient mouse model of atherosclerosis [92]. In a mouse model of renovascular hypertension Losartan demonstrated to prevent oxidative stress generation and may attenuate kidney oxidative injury [93]. As for ACE-Is, AKI cases were reported in bilateral renal artery stenosis or in solitary kidney [94, 95]. However, ARBs clearly-demonstrated efficacy and safety, fully justifies their use in unilateral renovascular disease. There are no clinical studies comparing the different molecules in renovascular disease setting, although in the CORAL trial has been employed Candesartan.

\section{CLINICAL ASPECTS OF RAAS BLOCKADE IN ARAS AND IN}

Detailed clinical evidence about RAAS modulators effectiveness in chronic IN is still lacking. This may be related to the aforementioned preoccupations raised by GFR reduction induced, in some cases, by this drug class. Currently, most RCTs enrolled mildmoderate ARAS subjects and/or excluding those with moderate to severe kidney dysfunction. Indeed, large trials, comparing the efficacy of different RAAS blocking agents classes and molecules, have not yet been published for IN. Consequently, our current knowledge about the safety and efficacy of RAAS inhibitors in chronic renal ischemia should be derived by from studies in ARAS and renovascular hypertension in patients with CKD.

In 1963, Dustan et al, performed the first trial exploring the medical management of renovascular hypertension. In this study conservative therapy consisted in a combination of three drugs (hydralazine, guanethidine, and a thiazide diuretic) chosen as an alternative to interventional approach in 32 subjects in which surgery was contraindicated for various reasons [96]. Of course, RAAS inhibitors could not be included and only less than a half of patients achieved a stable blood pressure and creatinine control. Nevertheless the authors suggested that medical approach could be a valid option in case of impracticable interventional management. Afterwards, many studies showed the efficacy of ACE-Is and ARBs in reducing blood pressure, cardiovascular risk and progression to ESRD, compared to other antihypertensive agents in different diseases $[97,98]$. Many papers emphasized their direct nephroprotective ability as already mentioned in previous paragraphs. The first study describing the use of an ACE-I, Captopril, in renovascular hypertension was published in 1983 by Hollenberg et al. [99]. This retrospective multicentre analysis enrolled 269 atherosclerotic renovascular disease patients, including bilateral renal artery and solitary kidney stenosis. Half of them had a baseline serum creatin- ine up to $1.5 \mathrm{mg} / \mathrm{dl}$ and $74 \%$ of patients achieved the blood pressure target [99]. This trial did not reported about effect on kidney function, so that we can argue that they were not relevant. Subsequently, other studies compared ACE-Is, primarily Enalapril and/or Enalapril plus hydrochlorothiazide versus standard triple therapy [100102].

Franklin et al., considered renal function as a safety outcome documenting an acute decline in renal function in 10 out of 75 subjects. Then, important observational studies by Tullis et al. in 1999, Losito et al. in 2005 and Hackman et al. in 2008 reviewed the efficacy of ACE-Is in ARAS, demonstrating that patients treated with ACE-Is exhibited a better long-term blood pressure control, even after revascularization. Furthermore, Hackman and colleagues found that therapy with ACE-Is was associated with a significantly lower risk of death for cardiovascular events and, remarkably, for maintenance dialysis initiation. In this large report, authors highlighted that, despite being at greater risk of developing AKI, patients who were treated with RAAS inhibitors for renovascular disease, had a significantly reduced incidence of requiring longterm haemodialysis. Therefore they concluded that the higher incidence of acute and in most-cases reversible renal dysfunction does not justify the choice of avoiding RAAS blockage in these patients. Besides, the AKI risk was well balanced by the renoprotective and overall cardioprotective effect. Unfortunately in all these papers there are no indications about the molecule and/or dosage applied.

After the introduction of percutaneous revascularization techniques, large multicenter trials like "Angioplasty and Stenting for Renal Artery Lesions" (ASTRAL), "Stent placement in patients with atherosclerotic renal artery stenosis" (STAR) and "The Cardiovascular Outcomes in Renal Atherosclerotic Lesions" (CORAL) mainly focused on comparing medical management versus interventional approaches. ACE-Is or ARBs were always part of the drug regimen and were apparently well tolerated [14].

In ASTRAL both interventional and medical groups had a $50 \%$ rate of patients treated with RAAS blocking drugs. However, drug preparation and dosage were locally established and not reported in the paper [15].

In 2009 the STAR trial was the first published study accounting renal protection as primary end point in ARAS patients under medical management versus PTRA. All patients were affected by impaired renal function (GFR $<80 \mathrm{~mL} / \mathrm{min}$ per $1.73 \mathrm{~m} 2$ ). The authors did not find any difference between invasive and conservative therapy, even after 2 years of follow-up. Furthermore this paper highlighted the advantage in this CKD-ARAS population of a multilevel integrated medical intervention consisted in the contemporary use of antihypertensive, lipid-lowering agents, antiplatelet and smoking cessation. Unfortunately they did not focus on RAAS blockade effect and drug preparation and dosage were not reported.

The more recent CORAL trial introduced the concept of "Optimal medical therapy" for renovascular disease patients. The results from this RCT further reduced enthusiasm of PTRA as an intervention for ARAS and were not without controversy. Possible explanations for this observed lack of benefit of PTRA include suboptimal selection of an appropriate population for which interventional approach was performed. It is already clear that patients who might benefit from revascularization are only those in which there is not irreversible kidney dysfunction. While patients affected by IN may not have an advantage from hemodynamic recovery, but they benefit of an integrated and well-structured medical approach.

"Optimal medical therapy" consisted of the combination of a multilevel cardiovascular risk factors correction. It includes smoking cessation, antiplatelet therapy and other protocol-driven medical therapies to control blood pressure, glucose and lipid levels in accordance with guidelines. Candesartan, with or without hydrochlorothiazide is the most studied drug in renovascular conditions. It should be administered together with ca-antagonist and statins 
(amlodipine-atorvastatin) to reach the maximum efficacy. The dose should be adjusted on the basis of blood pressure and lipid status. Candesartan might be replaced by ACE-Is in ARBs intolerant patients.

A major concern for using antiangiotensin drugs is their safety in patients with CKD In 2014, Evans et al., published a review based on CORAL's data disclosing that, even today, there is a very strong uncertainty on RAAS blockers prescription especially among IN patients. Clinicians do not yet seem convinced about safety and efficacy of this class as first choice therapy [17]. Often they are discouraged by the slight and mostly reversible creatinine increase that might appear during first weeks of treatment. Although these drugs have been safely used in many patients with serum creatinine levels up to $4 \mathrm{mg} / \mathrm{dl}$ with and without diabetes, with no significant onset of side effect such us AKI or hyperkalaemia, a common practice is to interrupt RAAS blocking agents when serum creatinine rises above $20-30 \%$ from baseline [103].

As yet, no clear guidelines on pharmacological therapeutic management of patients affected by ARAS and information about levels of renal dysfunction for RAAS blockers discontinuation have been published. Some authorities recommend monitoring serum creatinine levels and blood pressure every 3 months and noninvasive imaging of kidney (eg, using renal ultrasound and duplex scanning of the renal artery) to assess renal size and progression of stenotic lesions every 6-12 months.

Other studies suggest nuclear imaging because it can provide an estimate of blood flow and GFR for each kidney. This test could be useful in patients with normal renal function at baseline when the serum creatinine level alone cannot represent a sensitive indicator of progressive renovascular disease [13].

\section{CONCLUSIONS}

Optimal medical management of patients with renovascular disease and IN should be primarily directed to controlling BP and preservation of kidney function. IN must be treated as the CKD equivalent of coronary artery disease, focusing on rigorous management of hypertension, hyperglycemia, and hyperlipidemia. Lifestyle modifications, such as cessation of smoking, and antiplatelet therapy have reduced the risk of cardiovascular events in high-risk patients. Antihypertensive treatment should include RAAS blockade medication not only for their antihypertensive properties, but especially for those cardio and renoprotective.

More well designed RCTs are needed to comprehend which patients could better benefit of medical therapy and how chose the molecule and personalize the dosage. An optimal pharmacologic approach is crucial for a successful prevention of renal injury and cardiovascular events in this high-risk population.

\section{LIST OF ABBREVIATIONS}

$\mathrm{ACE}=$ Angiotensin-converting enzyme

ACE-Is $=$ ACE inhibitors

AngII $=$ Angiotensin II

ARAS $=$ Atherosclerotic renal artery stenosis

ARBs $=$ Angiotensin II receptor-blockers

ASIs $=$ Aldosterone synthase inhibitors

ASTRAL = Angioplasty and stenting for renal artery lesions trial

AT1 $=$ Angiotensin II type 1

AT2 $=$ Angiotensin II type 2

BBs $=\beta$-blockers

CKD $=$ Chronic kidney disease

CORAL $=$ Cardiovascular outcomes in renal atherosclerotic lesions

$\begin{array}{ll}\text { DRIs } & =\text { Direct renin inhibitors } \\ \text { ESRD } & =\text { End stage renal disease } \\ \text { FDA } & =\text { Food and drug administration } \\ \text { GFR } & =\text { Glomerular filtrate rate } \\ \text { PTA } & =\text { Percutaneous transluminal angioplasty } \\ \text { PTRA } & =\text { Percutaneous transluminal renal angioplasty } \\ \text { RAAS } & =\text { Renin Angiotensin Aldosterone system } \\ \text { RPTAs } & =\text { Renal Percutaneous transluminal angioplasty and } \\ \text { RCTs } & =\text { Renting } \\ \text { SNS } & =\text { Sympathetic nervous system } \\ \text { STAR } & =\text { Stent placement in patients with atherosclerotic } \\ & \end{array}$

\section{CONFLICT OF INTEREST}

The authors confirm that this article content has no conflict of interest.

\section{ACKNOWLEDGEMENTS}

Declared none.

\section{REFERENCES}

[1] Buemi M, Lacquaniti A, Bolignano D, Donato V, Fazio MR, Campo S, Coppolino G, Sturiale A: Dialysis and the elderly: an underestimated problem. Kidney \& blood pressure research, 31: 330-336, 2008.

[2] Textor SC, Wilcox CS: Renal artery stenosis: a common, treatable cause of renal failure? Annual review of medicine, 52: 421-442, 2001.

[3] Kalra PA, Guo H, Gilbertson DT, Liu J, Chen SC, Ishani A, Collins AJ, Foley RN: Atherosclerotic renovascular disease in the United States. Kidney international, 77: 37-43, 2010.

[4] Alcazar JM, Marin R, Gomez-Campdera F, Orte L, RodriguezJornet A, Mora-Macia J, Spanish Group of Ischaemic N: Clinical characteristics of ischaemic renal disease. Nephrology, dialysis, transplantation : official publication of the European Dialysis and Transplant Association - European Renal Association, 16 Suppl 1: 74-77, 2001.

[5] Cheung CM, Wright JR, Shurrab AE, Mamtora H, Foley RN, O'Donoghue DJ, Waldek S, Kalra PA: Epidemiology of renal dysfunction and patient outcome in atherosclerotic renal artery occlusion. Journal of the American Society of Nephrology : JASN, 13: 149-157, 2002.

[6] Coppolino G, Rivoli L, Bolignano D: Renal denervation for resistant hypertension. Cochrane Database of Systematic Reviews. John Wiley \& Sons, Ltd, 2015.

[7] Cianci R, Martina P, Gigante A, Di Donato D, Polidori L, Presta P, Labbadia R, Amoroso D, Zaccaria A, Barbano B, Fuiano G: Predictor factors for renal outcome in renal artery stenosis. European review for medical and pharmacological sciences, 17: 507-512, 2013.

[8] Olin JW, Melia M, Young JR, Graor RA, Risius B: Prevalence of atherosclerotic renal artery stenosis in patients with atherosclerosis elsewhere. The American journal of medicine, 88: 46N-51N, 1990.

[9] Krijnen P, van Jaarsveld BC, Steyerberg EW, Man in 't Veld AJ, Schalekamp MA, Habbema JD: A clinical prediction rule for renal artery stenosis. Annals of internal medicine, 129: 705-711, 1998.

[10] Coppolino G, Presta P, Saturno L, Fuiano G: Acute kidney injury in patients undergoing cardiac surgery. Journal of nephrology, 26: 32-40, 2013

[11] Mui KW, Sleeswijk M, van den Hout H, van Baal J, Navis G, Woittiez AJ: Incidental renal artery stenosis is an independent predictor of mortality in patients with peripheral vascular disease. Journal of the American Society of Nephrology : JASN, 17: 20692074, 2006.

[12] Cianci R, Zuccala A, Lucisano G, Barbano B, Martina P, Gigante A, Clemenzia G, Fuiano G: Have we new therapeutic strategies in the treatment of renovascular nephropathy? Current vascular pharmacology, 11: 531-542, 2013. 
[13] Plouin PF: Stable patients with atherosclerotic renal artery stenosis should be treated first with medical management. American journal of kidney diseases : the official journal of the National Kidney Foundation, 42: 851-857, 2003.

[14] Investigators A, Wheatley K, Ives N, Gray R, Kalra PA, Moss JG, Baigent C, Carr S, Chalmers N, Eadington D, Hamilton G, Lipkin G, Nicholson A, Scoble J: Revascularization versus medical therapy for renal-artery stenosis. The New England journal of medicine, 361: 1953-1962, 2009.

[15] Bax L, Woittiez AJ, Kouwenberg HJ, Mali WP, Buskens E, Beek FJ, Braam B, Huysmans FT, Schultze Kool LJ, Rutten MJ, Doorenbos CJ, Aarts JC, Rabelink TJ, Plouin PF, Raynaud A, van Montfrans GA, Reekers JA, van den Meiracker AH, Pattynama PM, van de Ven PJ, Vroegindeweij D, Kroon AA, de Haan MW, Postma CT, Beutler JJ: Stent placement in patients with atherosclerotic renal artery stenosis and impaired renal function: a randomized trial. Annals of internal medicine, 150: 840-848, W150-841, 2009.

[16] Cooper CJ, Murphy TP, Cutlip DE, Jamerson K, Henrich W, Reid DM, Cohen DJ, Matsumoto AH, Steffes M, Jaff MR, Prince MR, Lewis EF, Tuttle KR, Shapiro JI, Rundback JH, Massaro JM, D'Agostino RB, Sr., Dworkin LD, Investigators C: Stenting and medical therapy for atherosclerotic renal-artery stenosis. The New England journal of medicine, 370: 13-22, 2014.

[17] Evans KL, Tuttle KR, Folt DA, Dawson T, Haller ST, Brewster PS, He W, Jamerson K, Dworkin LD, Cutlip DE, Murphy TP, D'Agostino RB, Sr., Henrich W, Cooper CJ: Use of reninangiotensin inhibitors in people with renal artery stenosis. Clinical journal of the American Society of Nephrology : CJASN, 9: 11991206, 2014.

[18] Cianci R, Barbano B, Martina P, Gigante A, Polidori L, Lai S, Ascoli G, De Francesco I, Di Donato D, Fuiano G, Zuccala A: Nephroangiosclerosis and its pharmacological approach. Current vascular pharmacology, 9: 238-243, 2011.

[19] Lerman LO, Textor SC, Grande JP: Mechanisms of tissue injury in renal artery stenosis: ischemia and beyond. Progress in cardiovascular diseases, 52: 196-203, 2009.

[20] Hackam DG, Spence JD, Garg AX, Textor SC: Role of reninangiotensin system blockade in atherosclerotic renal artery stenosis and renovascular hypertension. Hypertension, 50: 998-1003, 2007.

[21] Basso N, Terragno NA: History about the discovery of the reninangiotensin system. Hypertension, 38: 1246-1249, 2001.

[22] Goldblatt H, Lynch J, Hanzal RF, Summerville WW: Studies on Experimental Hypertension : I. The Production of Persistent Elevation of Systolic Blood Pressure by Means of Renal Ischemia. The Journal of experimental medicine, 59: 347-379, 1934.

[23] Marekovic Z, Mokos I, Krhen I, Goreta NR, Roncevic T: Longterm outcome after surgical kidney revascularization for fibromuscular dysplasia and atherosclerotic renal artery stenosis. The Journal of urology, 171: 1043-1045, 2004

[24] Coppolino G, Buemi A, Bolignano D, Lacquaniti A, La Spada M, Stilo F, De Caridi G, Benedetto F, Loddo S, Buemi M, Spinelli F: Perioperative iloprost and endothelial progenitor cells in uremic patients with severe limb ischemia undergoing peripheral revascularization. The Journal of surgical research, 157: e129-135, 2009.

[25] Suresh M, Laboi P, Mamtora H, Kalra PA: Relationship of renal dysfunction to proximal arterial disease severity in atherosclerotic renovascular disease. Nephrology, dialysis, transplantation : official publication of the European Dialysis and Transplant Association - European Renal Association, 15: 631-636, 2000.

[26] Textor SC, Wilcox CS: Ischemic nephropathy/azotemic renovascular disease. Seminars in nephrology, 20: 489-502, 2000.

[27] Coppolino G, Bolignano D, Campo S, Loddo S, Teti D, Buemi M: Circulating progenitor cells after cold pressor test in hypertensive and uremic patients. Hypertension research : official journal of the Japanese Society of Hypertension, 31: 717-724, 2008.

[28] Lerman L, Textor SC: Pathophysiology of ischemic nephropathy. The Urologic clinics of North America, 28: 793-803, ix, 2001.

[29] Gloviczki ML, Glockner JF, Lerman LO, McKusick MA, Misra S, Grande JP, Textor SC: Preserved oxygenation despite reduced blood flow in poststenotic kidneys in human atherosclerotic renal artery stenosis. Hypertension, 55: 961-966, 2010.

[30] Urbieta-Caceres VH, Lavi R, Zhu XY, Crane JA, Textor SC, Lerman A, Lerman LO: Early atherosclerosis aggravates the effect of renal artery stenosis on the swine kidney. American journal of physiology Renal physiology, 299: F135-140, 2010.
[31] Textor SC, Novick A, Mujais SK, Ross R, Bravo EL, Fouad FM, Tarazi RC: Responses of the stenosed and contralateral kidneys to [Sar1, Thr8] AII in human renovascular hypertension. Hypertension, 5: 796-804, 1983.

[32] Fava C, Minuz P, Patrignani P, Morganti A: Renal artery stenosis and accelerated atherosclerosis: which comes first? Journal of hypertension, 24: 1687-1696, 2006.

[33] Chade AR, Lerman A, Lerman LO: Kidney in early atherosclerosis. Hypertension, 45: 1042-1049, 2005.

[34] Chade AR, Mushin OP, Zhu X, Rodriguez-Porcel M, Grande JP, Textor SC, Lerman A, Lerman LO: Pathways of renal fibrosis and modulation of matrix turnover in experimental hypercholesterolemia. Hypertension, 46: 772-779, 2005.

[35] Higashi Y, Sasaki S, Nakagawa K, Matsuura H, Oshima T, Chayama K: Endothelial function and oxidative stress in renovascular hypertension. The New England journal of medicine, 346: 19541962, 2002.

[36] Paneni F, Osto E, Costantino S, Mateescu B, Briand S, Coppolino G, Perna E, Mocharla P, Akhmedov A, Kubant R, Rohrer L, Malinski T, Camici GG, Matter CM, Mechta-Grigoriou F, Volpe M, Luscher TF, Cosentino F: Deletion of the activated protein-1 transcription factor JunD induces oxidative stress and accelerates agerelated endothelial dysfunction. Circulation, 127: 1229-1240, e1221-1221, 2013

[37] Osto E, Coppolino G, Volpe M, Cosentino F: Restoring the dysfunctional endothelium. Current pharmaceutical design, 13: 10531068, 2007.

[38] Textor SC: ACE inhibitors in renovascular hypertension. Cardiovascular drugs and therapy / sponsored by the International Society of Cardiovascular Pharmacotherapy, 4: 229-235, 1990.

[39] Ruster C, Wolf G: Renin-angiotensin-aldosterone system and progression of renal disease. Journal of the American Society of Nephrology : JASN, 17: 2985-2991, 2006.

[40] Covic A, Gusbeth-Tatomir P: The role of the renin-angiotensinaldosterone system in renal artery stenosis, renovascular hypertension, and ischemic nephropathy: diagnostic implications. Progress in cardiovascular diseases, 52: 204-208, 2009.

[41] Remuzzi G, Perico N, Macia M, Ruggenenti P: The role of reninangiotensin-aldosterone system in the progression of chronic kidney disease. Kidney international Supplement: S57-65, 2005.

[42] Pacurari M, Kafoury R, Tchounwou PB, Ndebele K: The ReninAngiotensin-aldosterone system in vascular inflammation and remodeling. International journal of inflammation, 2014: 689360, 2014

[43] Eddy AA: Interstitial fibrosis in hypercholesterolemic rats: role of oxidation, matrix synthesis, and proteolytic cascades. Kidney international, 53: 1182-1189, 1998.

[44] Allegra A, Coppolino G, Bolignano D, Giacobbe MS, Alonci A, D'Angelo A, Bellomo G, Teti D, Loddo S, Musolino C, Buemi M: Endothelial progenitor cells: pathogenetic role and therapeutic perspectives. Journal of nephrology, 22: 463-475, 2009.

[45] Basile DP, Leonard EC, Beal AG, Schleuter D, Friedrich J: Persistent oxidative stress following renal ischemia-reperfusion injury increases ANG II hemodynamic and fibrotic activity. American journal of physiology Renal physiology, 302: F1494-1502, 2012.

[46] Hartono SP, Knudsen BE, Zubair AS, Nath KA, Textor SJ, Lerman LO, Grande JP: Redox signaling is an early event in the pathogenesis of renovascular hypertension. International journal of molecular sciences, 14: 18640-18656, 2013.

[47] Kotchen TA, Lytton B, Morrow LB, Mulrow PJ, Shutkin PM, Stansel HC: Angiotensin and aldosterone in renovascular hypertension. Archives of internal medicine, 125: 265-272, 1970.

[48] Villarreal H, Arcila H, Diaz J, Sierra P: Effect of angiotensin on renal transport of sodium in renovascular hypertension. The American journal of cardiology, 19: 793-796, 1967.

[49] Palm F, Onozato M, Welch WJ, Wilcox CS: Blood pressure, blood flow, and oxygenation in the clipped kidney of chronic 2-kidney, 1clip rats: effects of tempol and Angiotensin blockade. Hypertension, 55: 298-304, 2010.

[50] Nussberger J, Aubert JF, Bouzourene K, Pellegrin M, Hayoz D, Mazzolai L: Renin inhibition by aliskiren prevents atherosclerosis progression: comparison with irbesartan, atenolol, and amlodipine. Hypertension, 51: 1306-1311, 2008.

[51] Simeoni M, Nicotera R, Colao M, Citraro ML, Pelagi E, Cerantonio A, Comi N, Coppolino G, Fuiano G: Direct inhibition of plasmatic renin activity with aliskiren: a promising but under- 
investigated therapeutic option for non-diabetic glomerulonephritis. International urology and nephrology, 2015.

[52] Atlas SA: The renin-angiotensin aldosterone system: pathophysiological role and pharmacologic inhibition. Journal of managed care pharmacy: JMCP, 13: 9-20, 2007.

[53] Campbell DJ: Circulating and tissue angiotensin systems. The Journal of clinical investigation, 79: 1-6, 1987.

[54] Nguyen G, Delarue F, Burckle C, Bouzhir L, Giller T, Sraer JD: Pivotal role of the renin/prorenin receptor in angiotensin II production and cellular responses to renin. The Journal of clinical investigation, 109: 1417-1427, 2002.

[55] Sumners C, de Kloet AD, Krause EG, Unger T, Steckelings UM: Angiotensin type 2 receptors: blood pressure regulation and end organ damage. Current opinion in pharmacology, 21: 115-121, 2015.

[56] Kamo T, Akazawa H, Komuro I: Pleiotropic Effects of Angiotensin II Receptor Signaling in Cardiovascular Homeostasis and Aging. International heart journal, 56: 249-254, 2015.

[57] Yang H, Zeng XJ, Wang HX, Zhang LK, Dong XL, Guo S, Du J, $\mathrm{Li} \mathrm{HH}$, Tang CS: Angiotensin IV protects against angiotensin IIinduced cardiac injury via AT4 receptor. Peptides, 32: 2108-2115, 2011.

[58] Allen AM, Zhuo J, Mendelsohn FA: Localization of angiotensin AT1 and AT2 receptors. Journal of the American Society of Nephrology: JASN, 10 Suppl 11: S23-29, 1999.

[59] Carey RM: The intrarenal renin-angiotensin system in hypertension. Advances in chronic kidney disease, 22: 204-210, 2015

[60] Paul M, Poyan Mehr A, Kreutz R: Physiology of local reninangiotensin systems. Physiological reviews, 86: 747-803, 2006.

[61] Mendoza-Torres E, Oyarzun A, Mondaca-Ruff D, Azocar A, Castro PF, Jalil JE, Chiong M, Lavandero S, Ocaranza MP: ACE2 and vasoactive peptides: novel players in cardiovascular/renal remodeling and hypertension. Therapeutic advances in cardiovascular disease, 9: 217-237, 2015.

[62] Burgelova M, Vanourkova Z, Thumova M, Dvorak P, Opocensky M, Kramer HJ, Zelizko M, Maly J, Bader M, Cervenka L: Impairment of the angiotensin-converting enzyme 2-angiotensin-(1-7)Mas axis contributes to the acceleration of two-kidney, one-clip Goldblatt hypertension. Journal of hypertension, 27: 1988-2000, 2009.

[63] Jackson B, Franze L, Sumithran E, Johnston CI: Pharmacologic nephrectomy with chronic angiotensin converting enzyme inhibitor treatment in renovascular hypertension in the rat. The Journal of laboratory and clinical medicine, 115: 21-27, 1990.

[64] Jackson B, Franze L, Sumithran E, Johnston C: Chronic angiotensin converting enzyme inhibition in the two-kidney, one clip hypertensive rat. Journal of hypertension Supplement : official journal of the International Society of Hypertension, 6: S408-411, 1988.

[65] Brown B, Hall AS: Renin-angiotensin system modulation: the weight of evidence. American journal of hypertension, 18: 127S133S, 2005.

[66] O'Donnell D: Renal failure due to enalapril and captopril in bilateral renal artery stenosis: greater awareness needed. The Medical journal of Australia, 148: 525-527, 1988.

[67] Jackson B, Matthews PG, McGrath BP, Johnston CI: Angiotensin converting enzyme inhibition in renovascular hypertension: frequency of reversible renal failure. Lancet, 1: 225-226, 1984.

[68] Ranadive SA, Chen AX, Serajuddin AT: Relative lipophilicities and structural-pharmacological considerations of various angiotensin-converting enzyme (ACE) inhibitors. Pharmaceutical research, 9: 1480-1486, 1992.

[69] Reynolds CH: Kinetics of inhibition of angiotensin converting enzyme by captopril and by enalapril diacid. Biochemical pharmacology, 33: 1273-1276, 1984.

[70] Guillaud F, Hannaert P: A computational model of the circulating renin-angiotensin system and blood pressure regulation. Acta biotheoretica, 58: 143-170, 2010.

[71] Remko M, Swart M, Bickelhaupt FM: Theoretical study of structure, $\mathrm{pKa}$, lipophilicity, solubility, absorption, and polar surface area of some centrally acting antihypertensives. Bioorganic \& medicinal chemistry, 14: 1715-1728, 2006.

[72] Wei L, Clauser E, Alhenc-Gelas F, Corvol P: The two homologous domains of human angiotensin I-converting enzyme interact differently with competitive inhibitors. The Journal of biological chemistry, 267: 13398-13405, 1992.
[73] Deddish PA, Wang LX, Jackman HL, Michel B, Wang J, Skidgel RA, Erdos EG: Single-domain angiotensin I converting enzyme (kininase II): characterization and properties. The Journal of pharmacology and experimental therapeutics, 279: 1582-1589, 1996.

[74] Bevilacqua M, Vago T, Rogolino A, Conci F, Santoli E, Norbiato G: Affinity of angiotensin I-converting enzyme (ACE) inhibitors for $\mathrm{N}$ - and $\mathrm{C}$-binding sites of human $\mathrm{ACE}$ is different in heart, lung, arteries, and veins. Journal of cardiovascular pharmacology, 28: 494-499, 1996

[75] Hornig B, Kohler C, Drexler H: Role of bradykinin in mediating vascular effects of angiotensin-converting enzyme inhibitors in humans. Circulation, 95: 1115-1118, 1997.

[76] Juillerat L, Nussberger J, Menard J, Mooser V, Christen Y, Waeber B, Graf P, Brunner HR: Determinants of angiotensin II generation during converting enzyme inhibition. Hypertension, 16: 564-572, 1990.

[77] Heintz B, Verho M, Brockmeier D, Luckel G, Maigatter S, Sieberth HG, Rangoonwala B, Bender N: Multiple-dose pharmacokinetics of ramipril in patients with chronic congestive heart failure. Journal of cardiovascular pharmacology, 22 Suppl 9: S36-42, 1993.

[78] Fabris B, Chen BZ, Pupic V, Perich R, Johnston CI: Inhibition of angiotensin-converting enzyme (ACE) in plasma and tissue. Journal of cardiovascular pharmacology, 15 Suppl 2: S6-13, 1990.

[79] Dinicolantonio JJ, Lavie CJ, O'Keefe JH: Not all angiotensinconverting enzyme inhibitors are equal: focus on ramipril and perindopril. Postgraduate medicine, 125: 154-168, 2013.

[80] Pilote L, Abrahamowicz M, Eisenberg M, Humphries K, Behlouli $\mathrm{H}$, Tu JV: Effect of different angiotensin-converting-enzyme inhibitors on mortality among elderly patients with congestive heart failure. CMAJ : Canadian Medical Association journal = journal de l'Association medicale canadienne, 178: 1303-1311, 2008.

[81] Burnier M: Angiotensin II type 1 receptor blockers. Circulation, 103: 904-912, 2001.

[82] Burnier M, Brunner HR: Angiotensin II receptor antagonists. Lancet, 355: 637-645, 2000.

[83] Israili ZH: Clinical pharmacokinetics of angiotensin II (AT1) receptor blockers in hypertension. Journal of human hypertension, 14 Suppl 1: S73-86, 2000.

[84] Dzau VJ, Sasamura H, Hein L: Heterogeneity of angiotensin synthetic pathways and receptor subtypes: physiological and pharmacological implications. Journal of hypertension Supplement : official journal of the International Society of Hypertension, 11: S13$18,1993$.

[85] Neutel J, Weber M, Pool J, Smith D, Fitzsimmons S, Chiang YT, Gatlin M: Valsartan, a new angiotensin II antagonist: antihypertensive effects over 24 hours. Clinical therapeutics, 19: 447-458; discussion 367-448, 1997.

[86] Elmfeldt D, George M, Hubner R, Olofsson B: Candesartan cilexetil, a new generation angiotensin II antagonist, provides dose dependent antihypertensive effect. Journal of human hypertension, 11 Suppl 2: S49-53, 1997.

[87] Mazzolai L, Burnier M: Comparative safety and tolerability of angiotensin II receptor antagonists. Drug safety, 21: 23-33, 1999.

[88] Fujino M, Miura S, Kiya Y, Tominaga Y, Matsuo Y, Karnik SS, Saku K: A small difference in the molecular structure of angiotensin II receptor blockers induces AT(1) receptor-dependent and independent beneficial effects. Hypertension research : official journal of the Japanese Society of Hypertension, 33: 1044-1052, 2010

[89] Hedner T, Oparil S, Rasmussen K, Rapelli A, Gatlin M, Kobi P, Sullivan J, Oddou-Stock P: A comparison of the angiotensin II antagonists valsartan and losartan in the treatment of essential hypertension. American journal of hypertension, 12: 414-417, 1999.

[90] Nickenig G, Harrison DG: The AT(1)-type angiotensin receptor in oxidative stress and atherogenesis: part I: oxidative stress and atherogenesis. Circulation, 105: 393-396, 2002.

[91] Mason RP, Jacob RF, Kubant R, Jacoby A, Louka F, Corbalan JJ, Malinski T: Effects of angiotensin receptor blockers on endothelial nitric oxide release: the role of eNOS variants. British journal of clinical pharmacology, 74: 141-146, 2012.

[92] Cheng XW, Song H, Sasaki T, Hu L, Inoue A, Bando YK, Shi GP, Kuzuya M, Okumura K, Murohara T: Angiotensin type 1 receptor blocker reduces intimal neovascularization and plaque growth in apolipoprotein E-deficient mice. Hypertension, 57: 981-989, 2011. 
[93] Polizio AH, Balestrasse KB, Gornalusse GG, Gorzalczany SB, Santa-Cruz DM, Yannarelli GG, Pena C, Tomaro ML: Losartan exerts renoprotection through $\mathrm{NAD}(\mathrm{P}) \mathrm{H}$ oxidase downregulation in a renovascular model of hypertension. Regulatory peptides, 156: 28-33, 2009.

[94] Wargo KA, Chong K, Chan EC: Acute renal failure secondary to angiotensin II receptor blockade in a patient with bilateral renal artery stenosis. Pharmacotherapy, 23: 1199-1204, 2003.

[95] Bavbek N, Kasapoglu B, Isik A, Kargili A, Kirbas I, Akcay A: Olmesartan associated with acute renal failure in a patient with bilateral renal artery stenosis. Renal failure, 32: 1115-1117, 2010.

[96] Hollenberg NK: Medical therapy for renovascular hypertension: a review. American journal of hypertension, 1: 338S-343S, 1988.

[97] Strippoli GF, Craig M, Deeks JJ, Schena FP, Craig JC: Effects of angiotensin converting enzyme inhibitors and angiotensin II receptor antagonists on mortality and renal outcomes in diabetic nephropathy: systematic review. Bmj, 329: 828, 2004.

[98] Jafar TH, Stark PC, Schmid CH, Landa M, Maschio G, de Jong PE, de Zeeuw D, Shahinfar S, Toto R, Levey AS, Group AS: Progression of chronic kidney disease: the role of blood pressure control, proteinuria, and angiotensin-converting enzyme inhibition: a pa- tient-level meta-analysis. Annals of internal medicine, 139: 244252, 2003.

[99] Hollenberg NK: Angiotensin converting enzyme inhibition and the kidney. Current opinion in cardiology, 3: S19-29, 1988.

[100] Franklin SS, Smith RD: Comparison of effects of enalapril plus hydrochlorothiazide versus standard triple therapy on renal function in renovascular hypertension. The American journal of medicine, 79: 14-23, 1985.

[101] Hodsman GP, Brown JJ, Cumming AM, Davies DL, East BW, Lever AF, Morton JJ, Murray GD, Robertson JI: Enalapril (MK421) in the treatment of hypertension with renal artery stenosis. Journal of hypertension Supplement : official journal of the International Society of Hypertension, 1: 109-117, 1983.

[102] Reams GP, Bauer JH: Enalapril versus triple-drug therapy in the treatment of renovascular hypertension. Drugs, 30 Suppl 1: 59-69, 1985.

[103] Bolignano D, Pisano A, Coppolino G: The Dark Side of Blocking RAS in Diabetic Patients with Incipient or Manifested Nephropathy. Experimental and clinical endocrinology \& diabetes : official journal, German Society of Endocrinology [and] German Diabetes Association, 2015. 